\title{
Infant lymphoblastic leukemia: a single centers 10 year experience
}

\author{
İnci Yaman-Bajin, Selin Aytaç, Barış Kuşkonmaz, Duygu Uçkan-Çetinkaya, Şule Ünal, \\ Fatma Gümrük, Mualla Çetin \\ Division of Pediatric Hematology, Department of Pediatrics, Hacettepe University Faculty of Medicine, Ankara, Turkey. \\ E-mail: inciyaman@gmail.com \\ Received: 25th February 2019, Revised: 20th March 2019, 3rd April 2019, Accepted: 4th April 2019
}

SUMMARY: Yaman-Bajin İ, Aytaç S, Kuşkonmaz B, Uçkan-Çetinkaya D, Ünal Ş, Gümrük F, Çetin M. Infant lymphoblastic leukemia: a single centers 10 year experience. Turk J Pediatr 2019; 61: 325-329.

Infant acute lymphoblastic leukemia (ALL) is a rare disease and consists of $4-5 \%$ of all childhood ALL. Despite improved survival rates in childhood ALL, infants with ALL have a worse prognosis. We aimed to evaluate the clinical features and treatment outcomes of our patients diagnosed with infant ALL at Hacettepe University, Pediatric Hematology Department between 1 January 2008 and 1 January 2018 retrospectively.

There were 13 patients with a median age of 7 months. Three of the patients were triplets born from a spontaneous monozygotic triplet pregnancy. Relapse were observed in 4 patients. Hematopoietic stem cell transplantation (HSCT) was performed for five patients. Relapse after HSCT was observed in 3 patients. After a median follow-up period of 18 months, 6 patients $(45 \%)$ ( 3 after HSCT and 3 who only received chemotherapy) were alive and in remission.

Prognosis of infant ALL is poor in that only half of the patients survive. Our results suggest that bone marrow transplantation seems to be a good and efficient choice of treatment for selected patients. However, there is still a big issue to decide which patient should undergo transplantation and more studies are needed to reevaluate the eligibility criteria for HSCT in this group of patients.

Key words: infant leukemia, acute lymphoblastic leukemia, chemotherapy.

Leukemia is the second most common cancer in children under 1 years of age after neuroblastoma. Both acute lymphoblastic leukemia (ALL) and acute myeloid leukemia (AML) can be observed. Although ALL is almost four times more frequent than AML in childhood, incidence among infants is very close. ${ }^{1}$ In the United States of America every year 160 new patients are diagnosed with leukemia during the infancy period and 90 of them are ALL while the other 70 cases are AML. ${ }^{2-4}$ Even though survival rates and treatment protocols do not differ with age for AML patients, survival rates among childhood ALL and infant ALL quite differ. Over the past 30 years' great progress has been made in the treatment of ALL of childhood. It is expected that eighty-five percent of the patients will be cured. Despite improved survival rates of childhood ALL, infants with ALL still have a worse prognosis and only half of the patients will survive. ${ }^{5}$ The largest infant ALL trial to date, Interfant-99 study included 482 infant ALL patients from 22 countries and achieved a 4 -year event-free survival (EFS) of $47 \%$ and survival of $55 \% .{ }^{6}$ That is why infant leukemia biology and treatment is an important research topic.

Infant lymphoblastic leukemia has a unique pattern with aggressive clinical and biological features. Some risk factors reported are white race, female gender, high birth weight $(>4 \mathrm{~kg})$, 
maternal use of drug and alcohol during pregnancy, radiation and solvent exposure, dietary intake of foods that act like natural DNA topoisomerase II inhibitors., ${ }^{7,8}$ Also the risk is increased for the twin sister or brother of a monozygotic twins diagnosed with infant leukemia because it has been shown that the onset of leukemia in infancy suggests a prenatal leukemogenic event, the occurrence of a single in utero leukemogenic event in one twin with generation of a clone can be passed to the other fetus by intraplacental metastasis ${ }^{1}$.The mixed lineage leukemia (MLL) gene rearrangements located on chromosome band $11 \mathrm{q} 23$ is the most important biological feature of infant ALL and accounts for $80 \%$ of the cases and distinguishes infant leukemia from childhood leukemias. ${ }^{9}$ Also CNS involvement (14\%) and leukemia cutis (50\%), hepatosplenomegaly and hyperleukocytosis (WBC>100000/ $\left.\mathrm{mm}^{3}(58 \%)\right)$ are much more frequently observed than in childhood leukemia. The immunophenotype of the infant leukemia blast cells are usually very young precursor B cells with CD34 and CD19 positivity and CD10 negativity (54\%) and myeloid antigen coexpression (28\%) can be observed more frequently than childhood leukemia.

In this study, we aimed to retrospectively evaluate the clinical and laboratory findings with treatment outcomes of our infant ALL patients

\section{Material and Methods}

Between 1 January 2008 and 1 January 2018, 210 patients were diagnosed with ALL at Hacettepe University, Pediatric Hematology Department. The study included 13 of them who were diagnosed under one year of age. ALL diagnosis was based on morphology, cytochemistry and flow cytometric immunophenotyping of bone marrow aspirate. The age, gender, signs and symptoms, laboratory assessment at diagnosis (leukocyte, hemoglobin, and platelet counts); CNS involvement; immunphenotype (B or T derived); treatment response; hematopoietic stem cell transplant (HSCT); relapse rate, time of follow-up were the analyzed variables (Table I). Data were collected from the hospital medical records.
The study protocol was approved by Hacettepe University Faculty of Medicine, Ethical Committee via the decision no. HEC 12/8741.

\section{Results}

The incidence of infant leukemia was found to be $6 \%(13 / 210)$ among all of our leukemia patients. There were nine boys and four girls with a median age of 7 months (range 1-12 months) and 9 out of 13 (69\%) were older than 6 months of age at the initial diagnosis. Interestingly 2 of 3 siblings born from spontaneous triplet pregnancy were diagnosed at the same time when they were 7 months old while the other sibling was diagnosed 4 months later when he was 11 months old. Physical examination revealed hepatosplenomegaly in 12 out of 13 patients and 1 patient had extramedullary involvement with subcutaneous nodules on the forehead.

Immunophenotyping revealed CALLA+ $B$ cell leukemia in 4 patients, CALLA- B cell in 7 patients and $T$ cell leukemia in 2 patients. Cytogenetic analysis showed $t(4 ; 11)$ positivity in 5 patients and 3 of them were the spontaneous triplets. Cerebrospinal Fluid were positive with blasts in 2 of the patients and traumatic for 4 patients.

Ten patients $(76 \%)$ were treated with Interfant protocols (Interfant $99(\mathrm{n}=4)$, Interfant 06 $(n=6))$ and 3 patients received Modified St. Jude Total XV protocol because they had been diagnosed when they were 11 or 12 months old. Relapse was observed in 4 patients.

HSCT was performed in five patients from matched related donor $(n=2)$, mismatched related donor $(n=1)$, and matched unrelated donor $(n=2)$. Relapse after HSCT was observed in 2 patients 3 and 4 months later; one of them continued with a second transplantation and survived. At the end of the follow-up period three of the five patients who had HSCT survived 91, 56, 32 months after the initial diagnosis. After a median of 29 months (range 3- 91 months) follow-up period, 6 patients (\%46) were alive and in remission; 3 after HSCT and 3 with chemotherapy without HSCT. 


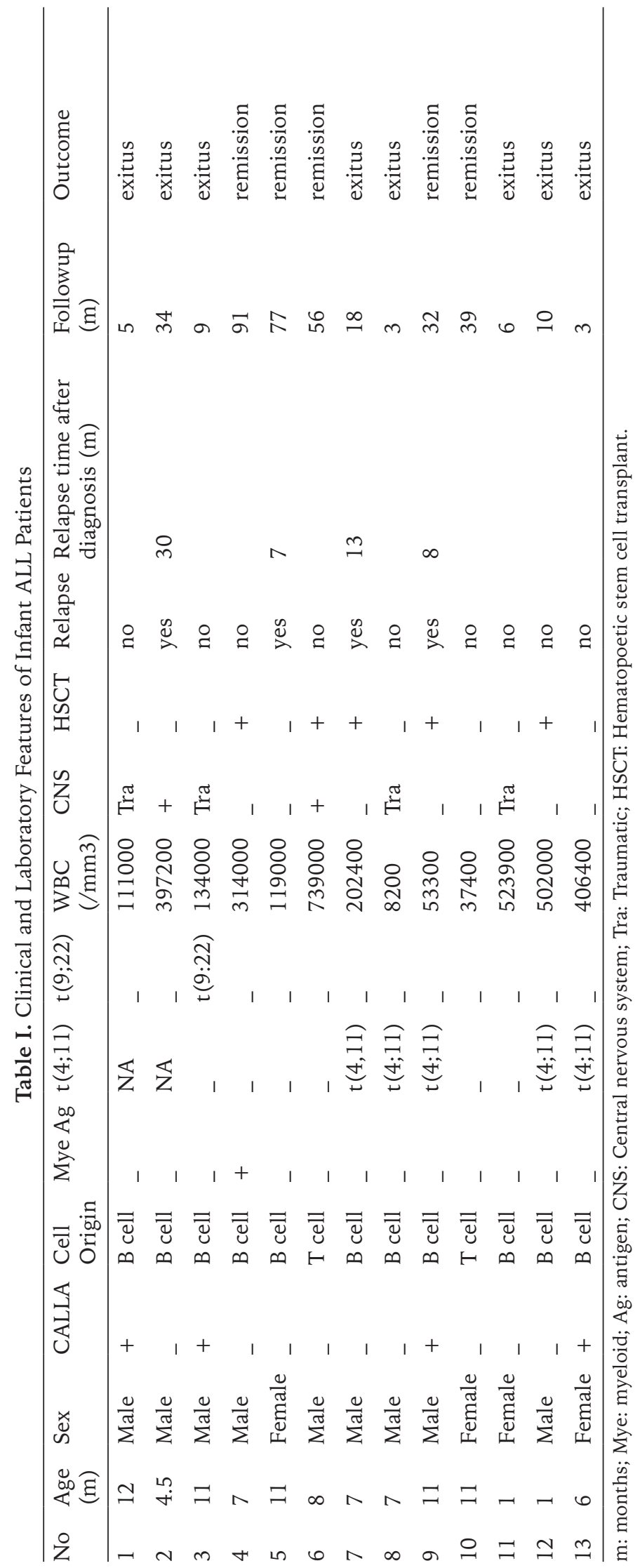




\section{Discussion}

Even though childhood leukemia is more frequently observed in boys, infant leukemia is known to be more common among girls ${ }^{1}$. But in our study, we had 13 patients and only 4 of them were girls (30\%).

The occurrence of a single in utero leukemogenic event in one twin with generation of a clone is passed to the other fetus by intraplacental metastasis. ${ }^{1}$ Two of the siblings of the triplets with infant leukemia in our study were diagnosed with CALLA negative, $t(4 ; 11)$ positive $B$ cell ALL when they were 7 months old. The third sibling who is the only one who survived among the triplets was diagnosed at the age of 11 months with CALLA positive, $t(4 ; 11)$ positive $B$ cell ALL.

It is known that the biological and clinical features of patients diagnosed under the age of 6 months are more aggressive. ${ }^{10,11}$ The age at diagnosis was 6 months or under in $4(30 \%)$ of our cases which all of them deceased.

Infant leukemia patients usually present with hepatosplenomegaly and extramedullary involvement ${ }^{1}$. Physical examination of all patients except one, revealed hepatosplenomegaly and 1 patient also had leukemia cutis.

Leukemia in children under one year of age usually presents with hyperleukocytosis. White blood cell count (WBC) >50000/ $\mathrm{mm}^{3}$ accounts for $66 \%$ and $\mathrm{WBC}>100000 /$ $\mathrm{mm}^{3} \quad$ accounts for $34 \%$ patients. ${ }^{12,13}$ Our study showed $84 \%(11 / 13)$ of our patients had WBC $>50000 / \mathrm{mm}^{3}$ while $76 \%(10 / 13)$ of our patients had $\mathrm{WBC}>100000 / \mathrm{mm}^{3}$ at the time of diagnosis.

The incidence of CNS involvement at the time of diagnosis in childhood ALL is $1.5 \%$ but it is much more common in infant leukemia. It is reported $14 \%$ in BFM group and $9 \%$ in Interfant 99 protocol. ${ }^{14}$ The high frequency of CNS involvement is another poor prognostic indicator for infant leukemia. ${ }^{15}$ In our study 2 patients were CNS positive while 4 patients had traumatic lumber punction.

Blastic cells are in precursor B cell phenotype for most of the infant leukemia patients. ${ }^{16}$
In our study we observed precursor B cell phenotype in 11 of the 13 patients while only 2 patients had $\mathrm{T}$ cell derived blastic cells. T cell phenotype is associated with more aggressive figure in EFS and overall survival (OS) ${ }^{17}$ But in our study, 2 patients with $\mathrm{T}$ cell leukemia were in remission at the end of the follow up period, 56 and 39 months after diagnosis.

Precursor B cell phenotype can be associated with CALLA positivity or negativity ${ }^{1}$. Most of our infant ALL patients (7/13) had CALLA negative precursor B cell phenotype consistent with the literature. Four of the patients were CALLA positive $B$ cell phenotype.

CALLA positive B cell leukemia patients are known to have better prognosis compared to patients with CALLA negative B cell phenotype and $\mathrm{T}$ cell phenotype., ${ }^{1,2}$ In our study we observed that $3 / 4$ of the patients with CALLA positive $B$ cell leukemia and $5 / 7$ of the patients with CALLA negative $B$ cell leukemia were deceased.

Myeloid antigen positivity is also more frequent especially for CALLA negative B cell phenotype. ${ }^{1,2}$ We had only one patient with myeloid antigen positivity and he was in remission at the end of the follow-up period.

MLL rearrangement is associated with poor prognosis $^{1,2}, 5$ patients were found to have $t(4 ; 11)$ in our study and 3 of them were the triplets. Only one (one of the triplets who was diagnosed later) survived among them.

Patients with infant leukemia respond well to chemotherapy but relapse occurs for almost half of them in one year., ${ }^{1,2}$ Relapses involve bone marrow in $80 \%$ of cases, the CNS in $30 \%$ and the testes in $8 \% .^{1,2}$ Relapse occurred in four of our patients and one of them was CNS and bone marrow relapse and the other 3 were bone marrow relapses.

Five patients received HSCT in our study and all of them were treated with Interfant 06 protocol prior to HSCT, 3 of them were $t(4 ; 11)$ positive and the other 2 were prednisone poor responders. Two of the patients with $t(4 ; 11)$ deceased while 1 patient with $t(4 ; 11)$ and 2 patients with prednisone poor response survived at the end of the follow-up period. HSCT is recommended for high risk patients 
in some trials but the occurrence of relapse after HSCT is common as well. Two patients relapsed after HSCT and they were both $t(4 ; 11)$ positive and the one who was CALLA positive survived after the second HSCT and the one who was CALLA negative deceased. So it is important to determine the group of patients who will benefit from HSCT.

Overall the prognosis is poor and international collaborative studies reported that 4 year EFS rates were between $28-54 \% .{ }^{18-20}$ Our patient group is small but the survival rates among patients who did (3/5) (60\%) and did not receive HSCT $(2 / 8)(25 \%)$ in our study group suggests that bone marrow transplantation seems to be a good and efficient choice of treatment. However, there is still an important issue concerning deciding which patient should undergo transplantation and more studies with larger patient groups are needed to reevaluate the eligibility criteria for HSCT in this group of patients.

\section{REFERENCES}

1. Kobos R, Shukla N, Armstrong SA. Infant leukemias. In: Orkin SH, Nathan DG, Ginsburg D, Look AT, Fisher DE, Lux SE. (eds). Nathan and Oski's Hematology and Oncology of Infancy and Childhood ( $8^{\text {th }}$ ed) Vol. 2. Philadelphia: Saunders, 2015: 16141625 .

2. Brown P. Treatment of infant leukemias: Challenge and promise. Hematology Am Soc Hematol Educ Program 2013; 2013: 596-600.

3. Masetti R, Rondelli R, Fagioli F, et al. Infants with acute myeloid leukemia treated according to the Associazione Italiana di Ematologia e Oncologia Pediatrica 2002/01 protocol have an outcome comparable to that of older children. Haematologica 2014; 99: e127-e129.

4. Masetti R, Vendemini F, Zama D, Biagi C, Pession A, Locatelli F. Acute myeloid leukemia in infants: Biology and treatment. Front Pediatr 2015; 3: 37.

5. Kotecha RS, Gottardo NG, Kees UR, Cole CH. The evolution of clinical trials for infant acute lymphoblastic leukemia. Blood Cancer J 2014; 4: e200.

6. Pieters R, Schrappe M, De Lorenzo P, et al. A treatment protocol for infants younger than 1 year with acute lymphoblastic leukaemia (Interfant-99): An observational study and a multicentre randomised trial. Lancet 2007; 370: 240-250.

7. Felix CA, Lange BJ. Leukemia in infants. Oncologist 1999; 4: 225-240.
8. Perez-Saldivar ML, Fajardo-Gutierrez A, SierraRamirez JA, et al; MIGICCL. Parental exposure to workplace carcinogens and the risk of development of acute leukemia in infants. Case-control study. Arch Med Res 2016; 47: 684-693.

9. Meyer C, Burmeister T, Gröger D, et al. The MLL recombinome of acute leukemias in 2017. Leukemia 2018; 32: 273-284.

10. Ibagy A, Silva DB, Seiben J, et al. Acute lymphoblastic leukemia in infants: 20 years of experience. J Pediatr (Rio J) 2013; 89: 64-69.

11. Bueno C, Montes R, Catalina P, Rodríguez R, Menendez P. Insights into the cellular origin and etiology of the infant pro-B acute lymphoblastic leukemia with MLL-AF4 rearrangement. Leukemia 2011; 25: 400-410.

12. Tomizawa D, Koh K, Hirayama M, et al. Outcome of recurrent or refractory acute lymphoblastic leukemia in infants with MLL gene rearrangements: A report from the Japan Infant Leukemia Study Group. Pediatr Blood Cancer 2009; 52: 808-813.

13. Mann G, Attarbaschi A, Schrappe M, et al; Interfant-99 Study Group. Improved outcome with hematopoietic stem cell transplantation in a poor prognostic subgroup of infants with mixed-lineageleukemia (MLL)-rearranged acute lymphoblastic leukemia: Results from the Interfant-99 Study. Blood 2010; 116: 2644-2650.

14. Silverman LB. Acute lymphoblastic leukemia in infancy. Pediatr Blood Cancer 2007; 49(7 Suppl): 1070-1073.

15. Pui $\mathrm{CH}$, Gaynon PS, Boyett JM, et al. Outcome of treatment in childhood acute lymphoblastic leukaemia with rearrangements of the $11 \mathrm{q} 23$ chromosomal region. Lancet 2002; 359: 1909-1915.

16. Zweidler-McKay PA, Hilden JM. The ABCs of infant leukemia. Curr Probl Pediatr Adolesc Health Care 2008; 38: 78-94.

17. Doerrenberg $\mathrm{M}$, Kloetgen $\mathrm{A}$, Hezaveh $\mathrm{K}$, et al. T-cell acute lymphoblastic leukemia in infants has distinct genetic and epigenetic features compared to childhood cases. Genes Chromosomes Cancer 2017; 56: 159-167.

18. Koh K, Tomizawa D, Moriya Saito A, et al. Early use of allogeneic hematopoietic stem cell transplantation for infants with MLL gene-rearrangement-positive acute lymphoblastic leukemia. Leukemia 2015; 29: 290-296.

19. Salzer WL, Jones TL, Devidas M, et al. Decreased induction morbidity and mortality following modification to induction therapy in infants with acute lymphoblastic leukemia enrolled on AALL0631: A report from the Children's Oncology Group. Pediatr Blood Cancer 2015; 62: 414-418.

20. Sison EAR, Brown P. Does hematopoietic stem cell transplantation benefit infants with acute leukemia? Hematology Am Soc Hematol Educ Program 2013; 2013: 601-604. 